\title{
New approach in assessing ecological state of environment in Kazan
}

\author{
Zamaletdinov R. I. \\ Natural and water management \\ Kazan (Privolzhsky) Federal University \\ Kazan, Russia
}

\author{
Zainullina G. T. \\ Natural and water management \\ Kazan (Privolzhsky) Federal University \\ Kazan, Russia
}

\author{
Panina V. G. \\ Natural and water management \\ Kazan (Privolzhsky) Federal University \\ Kazan, Russia
}

\begin{abstract}
The evaluation of the stability of development by the level of fluctuating asymmetry (FA) has been widely used in various studies. For a number of objects, such approach is impossible. We propose an approach for assessing the FA level for leguminous plants by the example of the Siberian pea shrub (Caragana arborescens Lam., 1785) in the conditions of Kazan. The obtained results showed the variability of the FA level in conditions of the multi-storey building and forest park area. The highest FA value was found in the forest-park area. The relationship between the level of FA and reproductive parameters (the relative magnitude of actual fertility) was found. The obtained results give us grounds to assume that the proposed methodological approach allows us to assess the ecological state of the territory with the help of the FA level in the environmental monitoring system in the city.
\end{abstract}

Keywords - fluctuating asymmetry, assessment, ecological state, urban ecosystems

\section{INTRODUCTION}

Today, it is widely believed that the anthropogenic factor in the type of impact on biological systems does not fundamentally differ from the aggregate of biotic and abiotic factors. However, in terms of intensity and combination of various human activities, the anthropogenic factor should be regarded as unique. The economic activity of man at the present time in terms of the volume and depth of the transformations is already comparable with the geological processes that took place in the past geological periods.

The most complete anthropogenic impact is concentrated in urbanized areas. In fact, modern cities represent the quintessence of the diversity of natural and anthropogenic environmental factors affecting living organisms. In this regard, the study of the reaction of living organisms to changes in habitat should be considered as adaptive mechanisms and apply them as a characteristic of the ecological state of urban areas.

It is in the cities now that most of the world's population lives. In this regard, there is a need to assess the environmental conditions of the environment. Among the many approaches to assessing the state of the urban environment, the most objective should be considered bioindication [5].

The organism and its environment are in a dynamic equilibrium. Under the influence of anthropogenic effects, the physical and chemical characteristics of the environment change lead to a disturbance of the dynamic equilibrium of natural ecosystems. Such situation makes studies of particular importance that determine the quality of the environment, the degree of its comfort for living organisms. Basic information on any global and local environmental changes is required based on the response of various ecosystem components. However, the diversity and intensity of anthropogenic influence on the natural environment continue to grow. Evaluation of the cumulative impact of the entire diversity of combinations of different impacts becomes generally impossible. The assessment of the quality of the natural environment in cities is especially important now. One of the modern and most promising methods for assessing the quality of the environment is the 
bioindication analysis, which provides an integral assessment of the situation, since living organisms summarize all biologically important environmental data and, without exception, reflect its state as a whole.

Recently, a method for estimating the level of fluctuating asymmetry (FA) has been widely used in our country as an indicator of the stability of the development of organisms in natural populations $[8$, 11, 12], including parasitic [7]. This approach seems promising for assessing and monitoring the status of natural populations of different species, as well as for assessing the quality of the environment $[4,14]$. It is recommended to use asymmetry indicators as indicators of the deviation of environmental conditions from optimal values. The stronger the negative impact, the greater the FA value of natural organisms [13]. Appropriate methods have been developed for a number of plant and animal organisms $[1,2]$. However, a significant part of these methods implies a significant proportion of subjectivity in the assessment.

This paper is an attempt to use a new approach in assessing the level of FA for bioindication of the urban environment.

The purpose of this work is to determine the possibilities of using the Siberian pea shrub (Caragana arborescens Lam., 1785) for assessing the state of the environment in urbanized areas (using the example of Kazan) by the FA method.

\section{MATERIAL AND METHODS}

The object for the study was a Siberian pea shrub or yellow acacia (Caragana arborescens Lam., 1785).

Material for this message was collected in the summer period of 2017. 235 leaves were analyzed in 4 habitats (Table 1), differing in terms of growth. The choice of habitats was built on the principle of their confinement to functional zones of multistorey buildings and a green zone [3].

TABLE I. CHARACTERISTICS OF THE COLLECTION POINTS

\begin{tabular}{|c|c|c|}
\hline Habitat & $\begin{array}{c}\text { Functional } \\
\text { area }\end{array}$ & Coordinates \\
\hline
\end{tabular}

\begin{tabular}{|l|c|c|}
\hline 1. Adoratsky & II & 55.839609, \\
Street & & 49.143263 \\
\hline 2. Golubyatniko & II & 55.838577, \\
va Street & & 49.106334 \\
\hline 3. The square of & II & 55.786014, \\
veterans & & 49.112909 \\
\hline 4. Forest Park & IV & 55.839496, \\
"Lebyazhye" & & 48.962955 \\
\hline
\end{tabular}

The difference between the area of the leaf on the right and the left side in pixels was used as the integral index of FA, then the difference in the two indicators was used as an arithmetic method.

To do this, the previously prepared leaves were scanned. The calculations were carried out using the Adobe Photoshop CC 2015 graphical editor, using the tools "Quick Selection" and "Measurement Log". We calculated the area of the leaf plate on the left and right in pixels. This difference was considered by us as the level of FA.

To identify statistically significant differences in different samples, we used Student's t-test. To assess the association between the level of FA and reproductive indicators, the Spearman rank correlation coefficient was used [9].

\section{RESULTS AND DISCUSSION}

We obtained the following data (Table 2). The greatest level of FA was obtained by us in the habitat 4 (forest park "Lebyazhye"). The minimum values were obtained in the built-up part of the city.

TABLE II. AVERAGE VALUES OF THE FA LEVEL IN THE STUDIED POPULATIONS OF THE SIBERIAN PEA SHRUB

\begin{tabular}{|l|c|}
\hline \multicolumn{1}{|c|}{ Habitat } & M $\pm \mathbf{m}$ \\
\hline 1. Adoratsky Street & II \\
\hline $\begin{array}{l}\text { 2. Golubyatnikova } \\
\text { Street }\end{array}$ & II \\
\hline $\begin{array}{l}\text { 3. The square of } \\
\text { veterans }\end{array}$ & II \\
\hline
\end{tabular}




\begin{tabular}{|l|l|}
\hline $\begin{array}{l}\text { 4. Forest Park } \\
\text { "Lebyazhye" }\end{array}$ & IV \\
\hline
\end{tabular}

When comparing the data, we obtained statistically significant differences between samples 1-2, 1-3, 1-4, 2-3, 2-4 (Table 3).

TABLE III. INDICATORS OF THE T-TEST OF THE FA LEVEL COMPARISON TESTER

\begin{tabular}{|c|c|c|c|c|}
\hline НАвттА & $\mathbf{1}$ & $\mathbf{2}$ & $\mathbf{3}$ & $\mathbf{4}$ \\
\hline 1. & - & & & \\
\hline 2. & $\mathbf{2 , 1 9}$ & - & & \\
\hline 3. & $\mathbf{4 , 5 4}$ & $\mathbf{2 , 4 2}$ & - & \\
\hline 4. & $\mathbf{4 , 1}$ & $\mathbf{2 , 5 7}$ & 0,63 & - \\
\hline
\end{tabular}

Here and further in bold, statistically significant differences are distinguished with significance level

$$
p<0.05 \text {. }
$$

There are several assumptions with what it may be connected. One of them is the relation of the Siberian pea shrub to the illumination of the terrain. Siberian pea shrub refers to photophilous plants. In habitat 4 (the forest park "Lebyazhye"), deciduous trees predominate, which limit access to the light to bushes, including the Siberian pea shrub. Probably, a lowered level of illumination affects the level of FA.

To test this hypothesis, we compared the values of the area of the leaf plate in all the samples studied. The results are shown in Table 4.

TABLE IV. AVERAGE VALUES OF THE AREA OF THE LEAF PLATE IN THE STUDIED POPULATIONS OF THE SIBERIAN PEA SHRUB

\begin{tabular}{|c|c|}
\hline Habitat & $\mathbf{M} \pm \mathbf{m}$ \\
\hline 1. & $139321,3 \pm 5385,61$ \\
\hline 2. & $130017,2 \pm 6889,34$ \\
\hline 3. & $184826,8 \pm 10734,93$ \\
\hline
\end{tabular}

4. $226168,2 \pm 11697,19$

The largest area of the leaf blade was found in locality 4.

The results of comparing the average values are given in Table 5.

TABLE V. INDICATORS OF THE T-TEST OF THE STUDENT COMPARING THE AVERAGE AREA OF THE LEAF PLATE

\begin{tabular}{|c|c|c|c|c|}
\hline НАВITAT & $\mathbf{1}$ & $\mathbf{2}$ & $\mathbf{3}$ & $\mathbf{4}$ \\
\hline 1. & - & & & \\
\hline 2. & 1,07 & - & & \\
\hline 3. & $\mathbf{4 , 3}$ & $\mathbf{4 , 3}$ & - & \\
\hline 4. & $\mathbf{6 , 7 4}$ & $\mathbf{7 , 0 8}$ & 2,60 & - \\
\hline
\end{tabular}

With the exception of samples 1 and 2, we found statistically significant differences. This gives grounds to assume that the shaded conditions have a negative impact on the development of the caragana.

A feature of the sample taken from the Veterans' Square (sample 3) is caring for the caragana, expressed in the form of regular cropping. The result, probably, is the compensatory growth of leaf plates. In general, this reflects our initial assumptions about the significance of the illumination level for leaf development in the caragana.

Against this background, interesting results were obtained by comparing the data on the assessment of the level of FA with other biological parameters. We compared it with the data of parallel work on the reproductive parameters of the caragana [15]. The results are shown in Table 6 .

TABLE VI. INDICATORS OF THE RANK CORRELATION COEFFICIENT OF THE SPEARMAN LEVEL OF FA WITH REPRODUCTIVE PARAMETERS 


\begin{tabular}{|c|c|c|c|}
\hline $\begin{array}{c}\text { Reproductive } \\
\text { indicators }\end{array}$ & Seed & Seeds & Oocytes \\
\hline $\begin{array}{c}\text { Coefficient } \\
\text { of rank } \\
\text { correlation } \\
\text { of Spearman }\end{array}$ & $\mathbf{0 , 8}$ & 0,4 & $-0,4$ \\
\hline
\end{tabular}

We detected statistically significant relations between the level of FA and the value of the proportion of mature seeds in caragana fruits $(\mathrm{r}=$ 0.8 ). This means that there are close positive relations between these parameters. To some extent, this contradicts the general view about the feedback between the level of FA and the intensity of the habitat $[6,10]$.

In our opinion, there is no fundamental contradiction here. We assume that the possible high level of seed ripening (the share of mature seeds in fruits) reduces the stability of the development of the leaf plate. Accordingly, monitoring of a significant number of parameters is necessary for an adequate assessment of the ecological state of the environment.

\section{Acknowledgment}

The obtained results give us grounds to assume that the proposed methodological approach allows us to assess the ecological state of the territory with the help of the FA level. To identify the full range of its variability, further research is needed.

\section{References}

[1] D.B. Gelashvili, I.V. Lobanova, E.Ya. Erofeeva, M.M. Naumova Influence of the forest pathological state of the birch layer on the magnitude of the fluctuating asymmetry of the leaf blade, Povolzhsky ekolog. Journal, 2007, № 6, pp. 106-115.

[2] L.N. Skripalshchikova, V.V. Stasova Bioindicative indicators of plant growth stability in disturbed landscapes, Siberian Forest Journal, 2014, № 2, pp. 62-72.

[3] I.Z. Khayrutdinov, Ecology of reptiles of urbanized territories: (on the example of Kazan), Abstract. dis .... Cand. Biol. Sciences of Kazan, 2010.

[4] S.F. Gilbert, Ecological developmental biology: developmental biology meets the real world, Developmental biology, 2001, V. 233, pp. 1-12.

[5] T.K. Parmar, D. Rawtani, Y.K. Agrawal, Bioindicators: the natural indicator of environmental pollution, FRONTIERS IN LIFE SCIENCE, 2016, VOL. 9, no. 2, pp. 110-118.

[6] P.A. Parson, Fluctuating asymmetry: an epigenetic measure of stress, Biol. Rev., 1990, no. 65, pp. 131-145.
[7] M. Pecinkova, L. A. Vøllestad, B. Koubkova, M. Gelnar, Asymmetries in the attachment apparatus of a gill parasite, Journal of Zoology, no. 272, 2007, pp. 406-414.

[8] N. V. Shadrin, E.V. Anufriieva, Size Polymorphism and Fluctuating Asymmetry of Artemia (Branchiopoda: Anostraca) Populations from the Crimea, Journal of Siberian Federal University, Biology, 2017, no. 10 (1), pp. 114-126.

[9] R. P. Sokal, F. Rohlf, Biometry, San Francisko: Freeman, 1981.

[10] L. Van Valen, A study of fluctuating asymmetry, Evolution, 1962, Vol. 16, pp. 125-142.

[11] V.L. Vershinin, E.A. Gileva, N.V. Glotov, Fluctuating Asymmetry of Measurable Parameters in Rana arvalis: Methodology, Russian Journal of Ecology, 2007, Vol. 38, No. 1, pp. 72-74.

[12] L.E. Yalkovskay, M.A. Fominykh, S.V. Mukhacheva, Yu.A. Davydova, A.V. Borodina, Fluctuating Asymmetry of Rodent Cranial Structures in an Industrial Pollution Gradient, Russian Journal of Ecology, 2016, Vol. 47, No. 3, pp. 281-288.

[13] V.M. Zakharov, Animal asymmetry: a populationphenogenetic approach, Moscow, Nauka, 1989.

[14] V.M. Zakharov, I.E. Trofimov, Morphogenetic Approach to Estimation of the Health of the Environment: Study of Developmental Stability, Russian Journal of Developmental Biology, 2017, Vol. 48, No. 6, pp. 369378.

[15] R.I. Zamaletdinov, S.M. Okulova, E.A. Gavrilova, A.A. Zakhvatova, R.R. Mingaliev, Materials on the study of the seed productivity of some leguminous plants (Fabaceae Lind., 1836) in the conditions of habitat urbanization, Ad -ta-journal of interdisciplinary research, 2017, Vol. 7, Is. pp. $47-50$. 